\title{
Modeling monthly mean temperatures for the mountain regions of Taiwan by generalized additive models
}

\author{
Bïng T. Guan ${ }^{a, *}$, Hsin-Wu Hsu ${ }^{a}$, Tsong-Huei Wey ${ }^{b}$, Li-Sung Tsao ${ }^{a}$ \\ a School of Forestry and Resource Conservation, National Taiwan University, Taipei 10617, Taiwan \\ ${ }^{\mathrm{b}}$ Experimental Forest, National Taiwan University, Chu-Shan 55750, Taiwan
}

\section{A R T I C L E I N F O}

Article history:

Received 9 December 2007

Received in revised form

3 August 2008

Accepted 17 August 2008

\section{Keywords:}

Lapse rate

Semi-parametric model

Spatial interpolations

Temperature

Thin plate regression splines

\begin{abstract}
A B S T R A C T
Taiwan is a mountainous island with a mountain flora that has a high degree of endemism. In order to facilitate the assessment of Taiwan's mountain flora integrity under various climate change scenarios, the objective of this study was to construct the monthly mean temperature models for the island's mountain regions (elevation $\geq 1000 \mathrm{~m}$ a.s.l.) based on data from 43 meteorology stations. We used a generalized additive modeling approach to construct the models, with elevation, easting, and northing co-ordinates, as the predictors. The effects of elevation were modeled mainly by linear or second-order polynomial functions, whereas the effects of location were modeled nonparametrically by thin plate regression splines. We used the leave-one-out cross-validation to validate the models, with mean errors, mean absolute errors, and root-mean-square of normalized errors as measures of generalization reliability. Spatial interpolations were then performed at a 1-km resolution. Judging by the adjusted $R^{2}$ and the proportion of deviance explained, all fitted models performed well. Monthly mean temperatures during the period of April to August decreased linearly with increasing altitude. The observed lapse rates were between 4.9 and $5.6{ }^{\circ} \mathrm{C} / \mathrm{km}$, with higher rates during the late spring and summer, and lower rates in the fall and early winter. For the first 3 calendar months, the lapse rates were between 3.2 and $3.6^{\circ} \mathrm{C} / \mathrm{km}$, but rose by $0.4-0.5^{\circ} \mathrm{C} / \mathrm{km}$ for each $\mathrm{km}$ of increase in elevation. The three performance measures suggested that the monthly predictions were reliable. The predictions were more reliable for regions from which most of the data were collected and less reliable at the edges of the mountain regions. Model analyses and spatial interpolation results suggested that the models realistically reflected the influence of the geographic location, terrain characteristics, dominant regional climatic features, and their interactions. Predictions also confirmed the existence of the Massenerhebung effect in central Taiwan. Our models also suggest that the alpine florae of the central and the southern regions could be more vulnerable to future winter temperature increases than that of the northern region. Although this study suffered from the lack of data from remote areas, a relatively dense network with quality stations and a good representation along the altitudinal gradient enabled this study to develop reliable models over a complex terrain. Future model improvements can be achieved by placing temporary monitoring points in less represented areas and then spatially interpolating between the temporary stations and the permanent ones.
\end{abstract}

(C) 2008 Elsevier B.V. All rights reserved.

\footnotetext{
* Corresponding author. Tel.: +886 2 33664628; fax: +886 223639247.
}

E-mail address: btguan@ntu.edu.tw (B.T. Guan). 


\section{Introduction}

Mountains cover about a quarter of the global land surface (Kapos et al., 2000). Because of mountains' unique environmental conditions and island-like nature (MacArthur, 1972; Haslett, 1997), mountain biodiversity often has a high degree of endemism (Körner, 2002). The investigation of global mountain biodiversity has attracted great attention during the past decade (e.g., Haslett, 1997; Körner and Spehn, 2002; Halloy and Mark, 2003), as it is likely to be highly vulnerable to climate change (Pounds et al., 1999; Thomas et al., 2004).

Situated in a subtropical region and with an area of about $36,000 \mathrm{~km}^{2}$, Taiwan is a mountainous island, the result of constant collisions between the Eurasian and Philippine Sea Plates. Mountains (elevation $\geq 1000 \mathrm{~m}$ a.s.l.) cover about $32 \%$ of the Island (Fig. 1), with more than 200 peaks surpassing $3000 \mathrm{~m}$ (the elevation of the highest peak is $3952 \mathrm{~m}$ ). Because of the steep altitudinal gradient, the island's flora is diverse. $\mathrm{Hsu}$ and Chen (2002) projected that, when the $\mathrm{CO}_{2}$ concentration doubles that of the 1961-1990 level, the mean temperature near Taiwan will likely increase between 0.9 and $2.7^{\circ} \mathrm{C}$ relative to the 1961-1990 mean. Thus, the future of Taiwan's mountain flora is of particular concern, as many of the species are endemic and are also the southernmost distributed species of their respective genus. Due to poor soil developments at high altitudes, many of Taiwan's subalpine and alpine plant species have already reached their respective limits of distribution. It is therefore unlikely that those species will be able to migrate

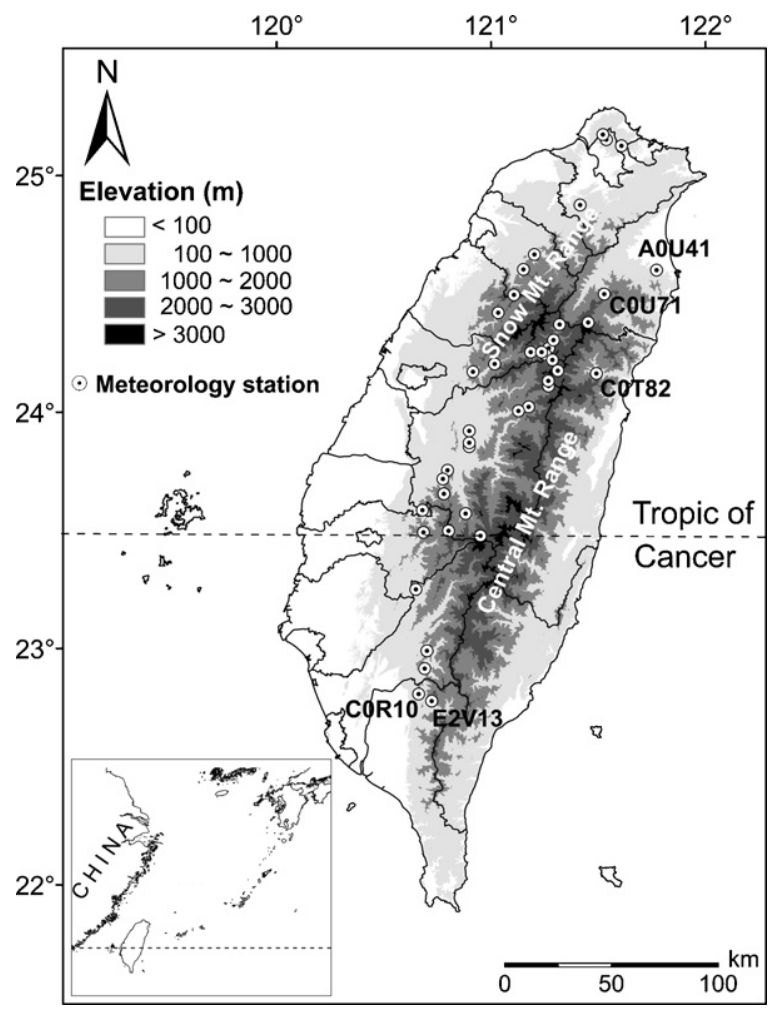

Fig. 1 - Topography of Taiwan and the locations of the 43 meteorology stations used in this study. Stations with an ID are considered as influential based on their Cook's distances. The digital terrain model (resolution $40 \mathrm{~m} \times \mathbf{4 0} \mathrm{m}$ ) is provided by Taiwan Forestry Bureau. upward under the projected temperature increases. Consequently, they might become extinct.

As temperature is an important factor in shaping mountain climates (Barry, 1992) and is a necessary input in climate change impact assessment models, assessing the current status and future integrity of Taiwan's mountain flora requires the construction of island-wide mountain region monthly mean temperature models, which have not been previously developed. Thus, the objective of this study was to construct such models based on a semi-parametric approach.

\section{Materials and methods}

\subsection{Climate and topography of Taiwan}

As Taiwan straddles the Tropic of Cancer (Fig. 1), its southern part is hot year-round, whereas the northern part is hot during the summer and relatively cool in the winter. Prevailing seasonal climatic features (e.g., monsoons) also significantly affect the island's temperature regime. Based on 21 first-order weather stations (elevations from 3 to $3852 \mathrm{~m}$ ) operated by Taiwan Central Weather Bureau, the island-wide mean annual temperature between 1971 and 2000 was about $21^{\circ} \mathrm{C}$ (http://www.cwb.gov.tw/V5e/index.htm), with January being the coldest month $\left(15^{\circ} \mathrm{C}\right)$ and July the warmest month $\left(26^{\circ} \mathrm{C}\right)$. Due to high mountains, East Asian monsoons, and typhoons, precipitation is high in Taiwan. Island-wide, the mean annual total precipitation between 1971 and 2000 was about $2600 \mathrm{~mm}$. In some mountain regions, the mean annual total precipitation exceeded $4500 \mathrm{~mm}$.

Areas that are below $100 \mathrm{~m}$ in elevation account for $37 \%$ of the island's total land area, hills between 100 and $1000 \mathrm{~m}$ cover $31 \%$, and mountains cover the remainder (Fig. 1). The Snow Mountain Range and the Central Mountain Range are the two dominant mountain ranges. Mountains extend from about $25^{\circ} \mathrm{N}$ to $22.3^{\circ} \mathrm{N}$, rising steeply from both the north and south toward the Tropic of Cancer, with high elevations $(>2500 \mathrm{~m}$ ) in the central regions of the Snow and the Central Mountain Ranges (Fig. 1).

\subsection{Data sources}

From the existing 187 meteorology stations (including firstorder, agricultural, cooperative, and auto-recording weather stations) in Taiwan, we first selected 43 stations that are at least $500 \mathrm{~m}$ in altitude and had a recording history of at least 10 years to 2005 . The elevations of the 43 stations are between 520 and $3845 \mathrm{~m}$. Their recording lengths ranged from 11 to 73 years (Table 1). Most of the stations are located in the central regions of the Snow and the Central Mountain Ranges (Fig. 1). Monthly mean temperature data for the 43 stations were obtained from Taiwan Central Weather Bureau.

We then correlated the 12 long-term monthly mean temperatures of each station with those of the other 42 stations. All Pearson's correlation coefficients were above 0.93, with the majority of the values above 0.98 . Thus, although different in recording history, long-term monthly means were consistent among the stations. We therefore retained all 43 stations for subsequent model development. 
Table 1 - Summary information for the 43 meteorology stations used in this study

Length of data record up to 2005 (years)

\begin{tabular}{lrcc} 
& \multicolumn{3}{c}{ (years) } \\
\cline { 2 - 4 } & $10-20$ & $20-40$ & 40 \\
\hline Elevation $(\mathrm{m})$ & 6 & 4 & 7 \\
$500-1000$ & 10 & 3 & 4 \\
$1000-2000$ & 6 & 1 & 2 \\
$>2000$ & & & \\
\hline
\end{tabular}

\subsection{Model development}

We used a generalized additive modeling (GAM, Hastie and Tibshirani, 1990) approach to construct our models. GAM assumes that the mean of a response variable (e.g., monthly mean temperature) depends on some predictors (e.g., elevation and location) through a link function, that is,

$l\left(\mu_{i}\right)=X_{i} \beta+f_{1}\left(x_{i 1}\right)+f_{2}\left(x_{i 2}\right)+f_{3}\left(x_{i 3}, x_{i 4}\right)+\cdots$

where () is a link function, $\mu_{i}=E\left(Y_{i}\right)$. In Eq. (1), $Y_{i}$ is the response variable with some exponential family distribution (e.g., a binomial, normal, or Poisson distribution), $X_{i}$ is the ith row of the parametric model matrix $\mathbf{X}, \boldsymbol{\beta}$ is the parameter vector, and $f_{j}$ are some smooth functions of the predictors, $x_{i}$ (Wood, 2006).

Due to its flexibility in modeling the nonlinear relationship between a response variable and its predictors, GAM has gained popularity in meteorological studies (e.g., Vislocky and Fritsch, 1995; Grieser et al., 2002).

\subsection{Monthly mean temperature models}

Two GAM models were developed for each monthly mean temperature variable:

Model I : $\mathrm{T}_{\mathrm{i}}=\beta_{0 \mathrm{i}}+\beta_{1 \mathrm{i}} \mathrm{e}+\mathrm{s}(\mathrm{x})+\mathrm{s}(\mathrm{y})+\mathrm{s}(\mathrm{x}, \mathrm{y})+\varepsilon_{i}, \quad \mathrm{i}=1,2, \ldots, 12$

Model II $: \mathrm{T}_{\mathrm{i}}=\beta_{0 \mathrm{i}}+\beta_{1 \mathrm{i}} \mathrm{e}+\beta_{2 \mathrm{i}} \mathrm{e}^{2}+\mathrm{s}(\mathrm{x})+\mathrm{s}(\mathrm{y})+\mathrm{s}(\mathrm{x}, \mathrm{y})+\varepsilon_{\mathrm{i}}$,

$i=1,2, \ldots, 12$

In both models, $T_{i}$ were the 43 monthly mean temperatures $\left({ }^{\circ} \mathrm{C}\right)$ of the ith month, $\beta_{0 i}\left({ }^{\circ} \mathrm{C}\right)$ was the intercept of the model, $\beta_{1 i}$ $\left({ }^{\circ} \mathrm{C} / \mathrm{km}\right)$ was the negative of the observed lapse rate (lapse rate henceforth) of the ith month, e represented the elevations $(\mathrm{km})$ of the stations, $\beta_{2 i}\left({ }^{\circ} \mathrm{C} / \mathrm{km}^{2}\right)$ was the rate of change of the lapse rate with elevation of the ith month, $s$ denoted a thin plate regression spline smoother, $x$ and $y$ were the easting and northing, respectively, co-ordinates $(m$, based on Taiwan Datum 1967) of the stations, and $\varepsilon_{i}$ were random errors. The basis dimension was chosen to be 5 for the $s(x)$ and $s(y)$ terms, and 25 for the $s(x, y)$ term. As the dimension only sets an upper bound on the flexibility of a smoother, its exact size is not critical (Wood, 2006).

Thin plate regression spline (Wood, 2003, 2006), which is an implementation of thin plate smoothing spline (Wahba, 1990), can nonparametrically smooth uni- and multi-variate predictors. Thin plate smoothing splines have been used extensively to spatially interpolate temperature and precipitation data (e.g., Hutchinson, 1998a,b; Price et al., 2000; Boer et al., 2001; Jarvis and Stuart, 2001; Sansom and Tait, 2004; McKenney et al., 2006; Tait et al., 2006).

Both GAM models were semi-parametric, as we modeled the effects of elevation mainly by parametric functions and the spatial (location) effects nonparametrically. Please note that in both models the nonparametric terms would also account for some elevation effects not explained by the parametric term(s). Such a modeling approach enables us to estimate monthly lapse rates and account for the spatial effects simultaneously. We used Model II to determine whether mean temperatures decreased nonlinearly with increasing altitude as in some tropical regions (e.g., Fox and Bloom, 1994). We used the Akaike Information Criterion (AIC) for model selection.

As the main objective of this study was to develop islandwide prediction models, we considered only the elevation and the location of the 43 stations, and ignored other station attributes (e.g., aspect, valley, or slope) that can exert significant influence on the recorded temperatures of a station (Barry, 1992).

\subsubsection{Model validations}

We adopted the leave-one-out (station withholding) crossvalidation approach (Stone, 1974) to validate our models. Under the validation approach, each station was excluded sequentially, and the mean temperature models developed from the remaining 42 stations were used to predict the mean temperatures of the station excluded. Validations were conducted after selecting the most appropriate mean temperature models. We used mean errors or $\operatorname{ME}\left(E_{1},{ }^{\circ} \mathrm{C}\right)$, mean absolute errors or $\operatorname{MAE}\left(E_{2},{ }^{\circ} \mathrm{C}\right)$, and root-mean-square of normalized errors or RMSNE $\left(E_{3}\right)$ to measure the generalization reliability and precision of a model.

Let $\mathrm{O}_{i}$ be an observed monthly mean temperature at the ith station, $P_{-i}$ be the predicted monthly mean temperature for the ith station based on the model developed without the ith station, and $\sigma_{-i}$ be the estimated residual error standard deviation of the model developed without the ith station. Then, for each monthly mean temperature model, the three generalization performance measures were defined as

$E_{1}=\frac{1}{n} \sum_{i=1}^{n}\left(O_{i}-P_{-i}\right)$

$E_{2}=\frac{1}{n} \sum_{i=1}^{n}\left|O_{i}-P_{-i}\right|$, and

$E_{3}=\left(\frac{1}{n} \sum_{i=1}^{n}\left(\frac{O_{i}-P_{-i}}{\sigma_{-i}}\right)^{2}\right)^{1 / 2}, n=43$

If a model is adequate, then ME and MAE should be approximately 0, and RMSNE should be close to 1 (Cressie, 1993).

We used a modified Cook's distance $\left(C_{d}\right.$, Eubank, 1985), which is closely related to the deleted residual (i.e., $O_{i}-P_{-i}$ ), to measure the influence of each station on the fitted models. We regarded a station as influential if its $C_{d}$ value was greater than 0.2 in at least three models. 


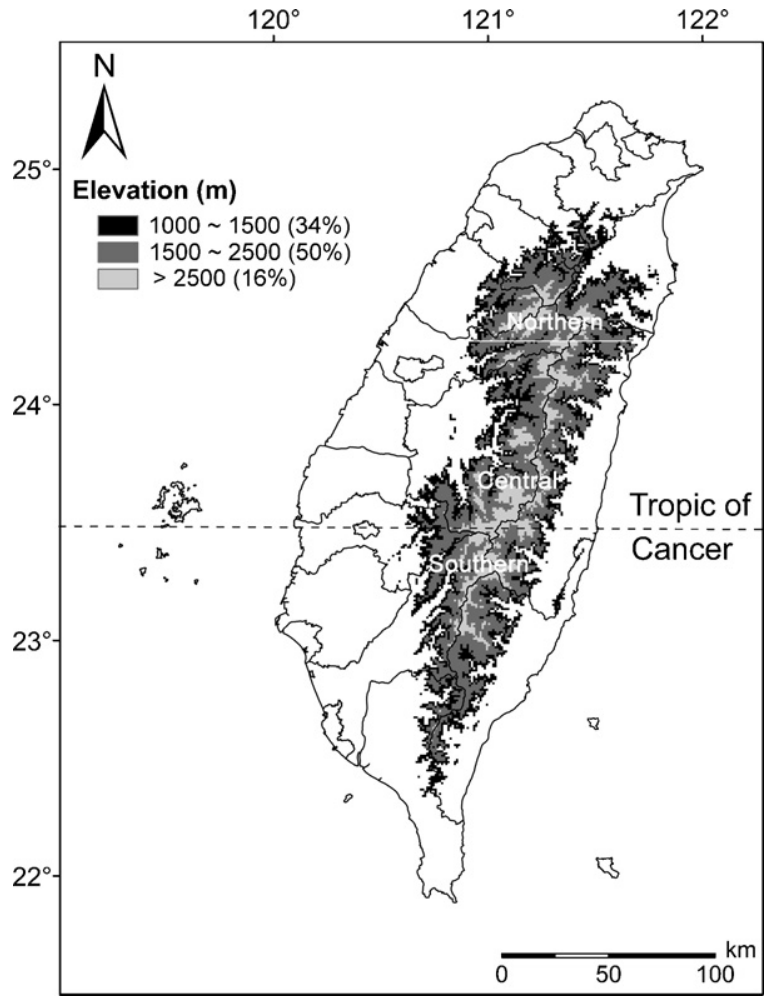

Fig. 2 - Spatial interpolation data extracted at a 1-km resolution from a digital elevation model (resolution $40 \mathrm{~m} \times \mathbf{4 0} \mathrm{m}$ ) of Taiwan.

\subsection{Spatial interpolations}

Based on a digital terrain model of Taiwan (resolution $40 \mathrm{~m} \times 40 \mathrm{~m}$ ) from Taiwan Forestry Bureau, we extracted 11,478 data points (at a $1-\mathrm{km}$ resolution) above $1000 \mathrm{~m}$ in elevation (Fig. 2). About $66 \%$ of those points were above $1500 \mathrm{~m}$. The northernmost mountain region of Taiwan, an isolated volcanic mountain system near Taipei, was excluded from the interpolations. At a 1-km resolution, only two isolated points (the summit areas) from that mountain system would be included. Based on the existing climate region classification of Taiwan, we divided the data points into the northern, central, and southern regions, with the Tropic of Cancer as the boundary between the central and southern regions (Fig. 2). The mean elevations for the three regions are 1834, 1892, and $1818 \mathrm{~m}$, respectively.

The monthly mean temperatures for each data point were predicted from the fitted models. We then derived the mean spring (March-May), summer (June-August), fall (SeptemberNovember), and winter (December-February) temperatures of each point by averaging its predicted monthly means, without weighting the number of days in each month.

All statistical analyses were conducted in $\mathrm{R}$ ( $\mathrm{R}$ Development Core Team, 2007). We used the gam function of the $\mathrm{mgcv}$ package of R (Wood, 2006) to perform GAM analyses, with the smoothing parameter determined by the generalized crossvalidation method (Craven and Wahba, 1979). For all models, we used the identity function as the linked function and assumed that $\varepsilon_{i}$ were distributed as $N\left(0, \sigma^{2} I\right)$.

\section{Results}

\subsection{Model fitting}

Based on AIC, Model II was selected for the first 3 calendar months, whereas Model I was a better choice for the remaining months (Table 2). Both the adjusted $R^{2}$ and the proportion of deviance explained were above 0.97 for all models. As most of the nonparametric terms in each fitted model were significant, the thin plate regression spline smoothers successfully accounted for the spatial variations. Based on the residual diagnostics (the Shapiro-Wilk normality test, residuals-fitted values plot, and semivariogram), residuals of each fitted model did not significantly violate the normality, equal variance, and independence assumptions.

\subsection{Lapse rates}

Between April and December, the estimated lapse rates ranged from about 4.9 to $5.6^{\circ} \mathrm{C} / \mathrm{km}$, with higher values for the late

Table 2 - Estimated parameters (standard errors) for the parametric terms and estimated degrees of freedom (EDF) for the nonparametric terms for the 12 monthly mean temperature models

\begin{tabular}{|c|c|c|c|c|c|c|}
\hline \multirow[t]{2}{*}{ Model } & \multicolumn{3}{|c|}{ Parameters } & \multicolumn{3}{|c|}{ EDF } \\
\hline & $\beta_{0}\left({ }^{\circ} \mathrm{C}\right)$ & $\beta_{1}\left({ }^{\circ} \mathrm{C} / \mathrm{km}\right)$ & $\beta_{2}\left({ }^{\circ} \mathrm{C} / \mathrm{km}^{2}\right)$ & $x$ & $y$ & $(x, y)$ \\
\hline January & $16.33(0.50)$ & $-3.24(0.61)^{* *}$ & $-0.47(0.15)^{* *}$ & $2.32^{* *}$ & $1.51^{* *}$ & $17.23^{* *}$ \\
\hline February & $17.60(0.44)$ & $-3.61(0.54)^{* *}$ & $-0.42(0.13)^{* *}$ & $2.63^{* *}$ & $1.52^{* *}$ & $16.84^{* *}$ \\
\hline March & $19.70(0.48)$ & $-3.22(0.58)^{* *}$ & $-0.50(0.14)^{* *}$ & $2.44^{* *}$ & $1.56^{* *}$ & $15.77^{* *}$ \\
\hline April & $24.18(0.27)$ & $-5.43(0.18)^{* *}$ & & $2.52^{* *}$ & $0.99^{* *}$ & $12.89^{* *}$ \\
\hline May & $26.43(0.30)$ & $-5.58(0.20)^{* *}$ & & $3.06^{* *}$ & $1.00^{* *}$ & $15.48 * *$ \\
\hline June & $28.04(0.32)$ & $-5.56(0.21)^{* *}$ & & $2.88^{* *}$ & $1.00^{* *}$ & $14.96^{* *}$ \\
\hline July & $28.84(0.33)$ & $-5.62(0.22)^{* *}$ & & $3.71^{* *}$ & 0.27 & $6.58^{*}$ \\
\hline August & $28.46(0.30)$ & $-5.61(0.20)^{* *}$ & & $2.62^{* *}$ & $1.00^{* *}$ & $15.90^{* *}$ \\
\hline September & $27.18(0.30)$ & $-5.50(0.20)^{* *}$ & & $3.68^{* *}$ & $0.41^{*}$ & $6.42^{*}$ \\
\hline October & $25.05(0.30)$ & $-5.30(0.20)^{* *}$ & & $3.80^{* *}$ & $0.76^{* *}$ & $6.40^{*}$ \\
\hline November & $21.97(0.32)$ & $-4.93(0.21)^{* *}$ & & $3.45^{* *}$ & $1.03^{*}$ & $11.32^{* *}$ \\
\hline December & $19.02(0.32)$ & $-5.00(0.21)^{* *}$ & & $3.74^{* *}$ & $2.56^{*}$ & $3.40^{*}$ \\
\hline
\end{tabular}


spring and summer months, and lower values for the late fall and early winter months. For the first 3 calendar months, the lapse rates were between 3.2 and $3.6^{\circ} \mathrm{C} / \mathrm{km}$, but rose by 0.4 $0.5^{\circ} \mathrm{C} / \mathrm{km}$ for each $\mathrm{km}$ of increase in elevation (Table 2). The estimated lapse rates and their seasonal trend matched those found in mountain regions of Europe (Rolland, 2003). The clear seasonal trend suggested that we had a good representation of stations along the sharp altitudinal gradient (Rolland, 2003).

\subsection{Nonparametric smoothing}

The estimated degrees of freedom (EDF) required for smoothing the northing co-ordinate were between 0.3 and 2.6, and between 2.3 and 3.8 for the easting co-ordinates (Table 2). The large EDF required for smoothing the two co-ordinates simultaneously suggested that the monthly means were strongly influenced by the interactions between the geographic location and terrain features.

Mean temperatures increased linearly from north to south, except in July and December. As the entire island is hot during July, a relatively flat north-south trend was expected. The nonlinear north-south trend in December reflected the highly uneven cooling latitudinally during that month, when hot southerly winds still affect southern Taiwan while cold northerly winds intensify their influence over northern Taiwan. The EDF for the first 3 months also indicated uneven latitudinally cooling, but to a lesser degree.

The nonlinear west-east trend, which was similar in shape throughout the year, indicated that mean temperatures initially increased slightly toward the east, decreased in the central high mountain regions, and then increased sharply further east. The trend reflected the locations and the influences of the two major mountain ranges. The initial increase was mainly due to adiabatic heating on the east side of the Snow Mountain Range, and the subsequent increase east of the Central Mountain Range reflected both adiabatic heating and lower elevations.

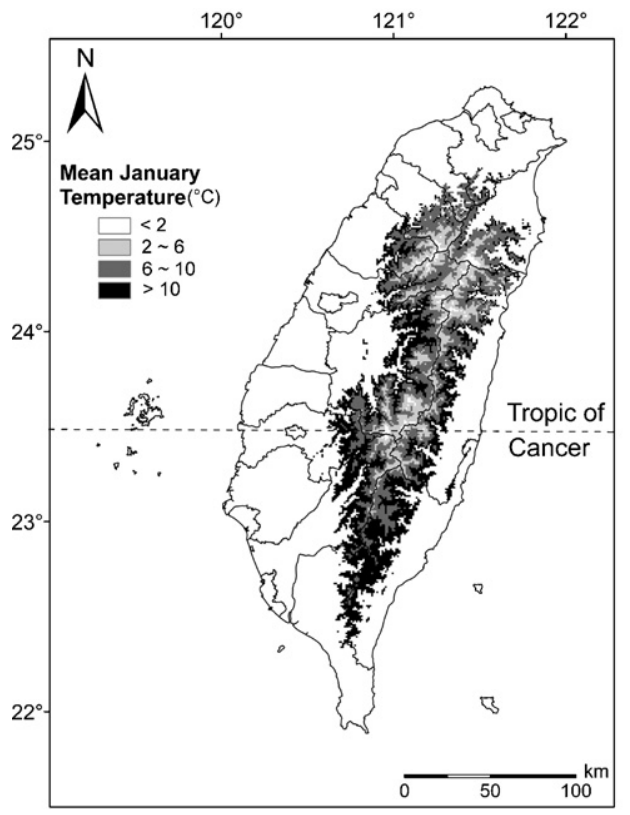

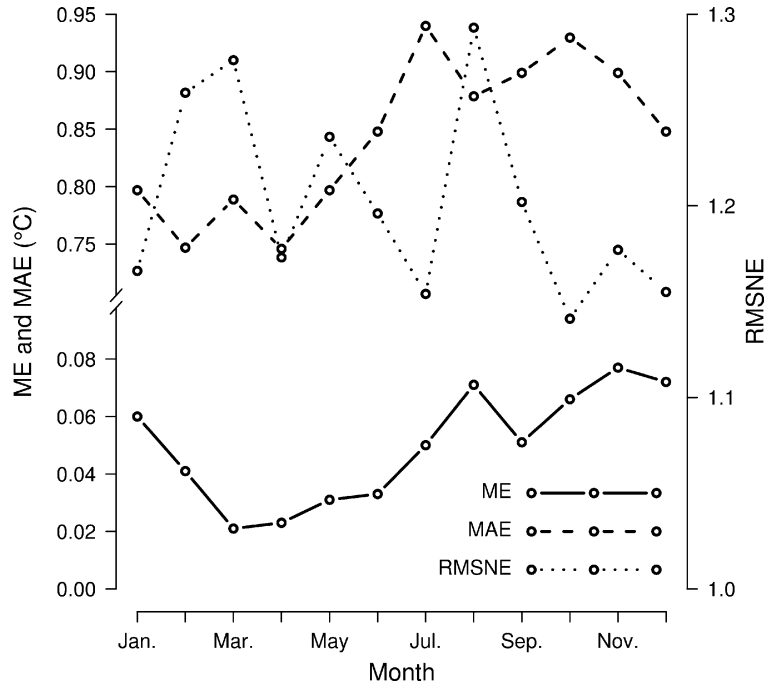

Fig. 3 - Mean error (ME), mean absolute error (MAE), and root-mean-square of normalized error (RMSNE) for predicted monthly means based on the leave-one-out cross-validation.

\subsection{Cross-validations}

The ME values were less than 0.1 for all monthly means (Fig. 3), with the lowest and the highest values occurring in March and November, respectively. The error measure indicated that our models tended to underestimate monthly mean temperatures slightly. The MAE values were between 0.75 and 0.95 , with the lowest and the highest values occurring in April and July, respectively. Both error measures followed a similar trend, with a smaller amount of generalization errors in spring, and a greater amount of errors in summer and fall. The RMSNE values were between 1.1 and 1.3. The predictions were less precise for February, March, and August. With respect to the

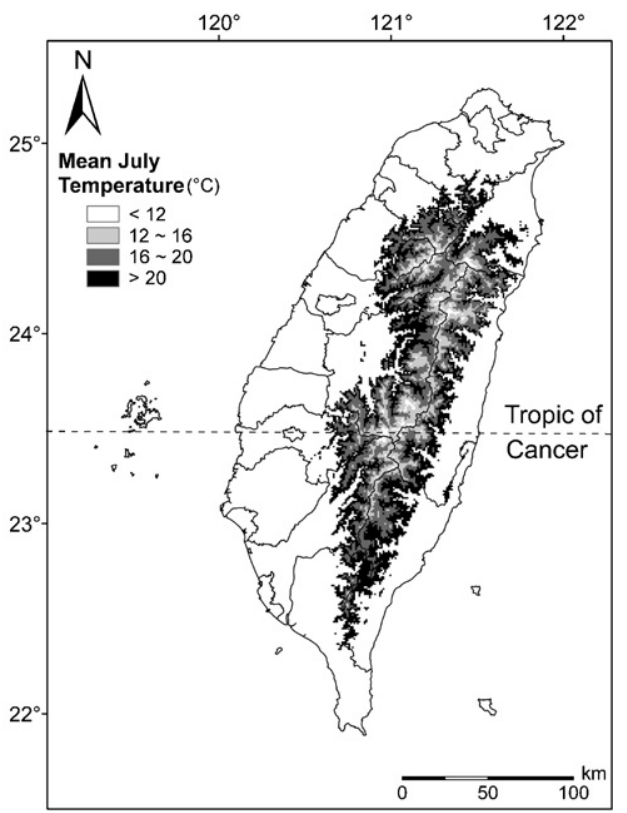

Fig. 4 - Predicted monthly mean temperatures of January and July for the mountain regions of Taiwan. 


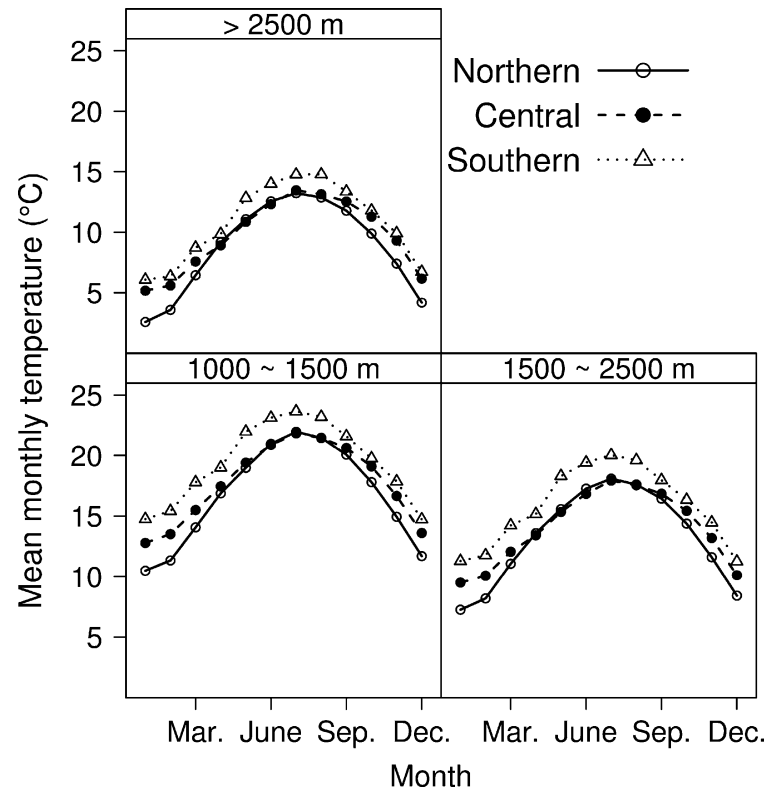

Fig. 5 - Predicted monthly mean temperatures of the northern, central, and southern mountain regions in three altitudinal zones for the mountain regions of Taiwan.

monthly means, the RMNSE values suggested that our models accounted for a relatively large portion of the sources of variability in the observed data.

Five stations located at the edges of Taiwan's mountain regions were regarded as influential (Fig. 1). Station A0U41 was the most influential one, as its $C_{d}$ values were greater than 1.5 in all fitted models. Station COR10 was also influential in eight models. Its $C_{d}$ values ranged from 0.2 to 0.6 in those models. The other three stations were regarded as mildly influential, as their $C_{d}$ values were all less than 0.4. The mean temperatures of the five stations were consistently either underestimated (AOU41 and E2V13) or overestimated (COT82, COR10, and COU71). Thus, temperature predictions for those areas were less accurate.

\subsection{Spatial interpolations}

Fig. 4 shows the predicted mean temperatures for January (the coldest month) and July (the warmest month). For both months, the lowest mean temperatures occurred in the ridge areas of the Snow and Central Mountain Ranges, whereas the highest mean values occurred at the low elevation areas. All other monthly mean temperature spatial interpolations showed a similar pattern. Fig. 5 summarizes the predicted monthly means of the three mountain regions in three altitudinal zones. The southern region had higher temperatures year-round in all altitudinal zones. During the summer months, the mean temperatures were about the same for the northern and the central region in all altitudinal zones. Fig. 5 also suggests that the three regions warmed up and cooled down unevenly. Compared to the other two regions, the northern region warmed up more quickly in early spring and cooled down faster in early fall, especially in the lowest elevation zone.

The differences in the predicted island-wide monthly mean temperatures along the elevation gradient were smaller in late winter and early spring, and larger in summer and early fall (Fig. 5). Table 3 shows the mean seasonal temperatures of three weather stations ( $\geq 40$ years in recording length) with a similar geographic location, but different altitudes. Our predictions matched the observed seasonal trends.

Fig. 6 shows the predicted mean seasonal temperature patterns. Most of the mountain regions had winter mean temperatures of less than $10^{\circ} \mathrm{C}$ (defined as low temperature in Taiwan), except for the lower elevation areas and the southern region of the Central Mountain Range. The northern region was the coldest of the three regions. Another cold spot was the high elevation areas close to the Tropic of Cancer, where most of the high peaks of the Central Mountain Range are located. In the spring, only areas above $2900 \mathrm{~m}$ had mean temperatures less than $5^{\circ} \mathrm{C}$, and the low temperatures were restricted to areas above $1900 \mathrm{~m}$. In the summer, most of the mountain regions were still relatively cool, and only areas below $1200 \mathrm{~m}$ had mean temperatures higher than $20^{\circ} \mathrm{C}$. In the fall, the mean temperature for areas above $1500 \mathrm{~m}$ was below $15^{\circ} \mathrm{C}$, while a greater part of the southern mountain region was still relatively warm.

Our models predicted that the mean winter temperature for areas below $2500 \mathrm{~m}$ in the northern mountain region would be about $4{ }^{\circ} \mathrm{C}$ lower than for those in the southern region (Figs. 5 and 6). The southern region was warmer than the northern region during the summer. Both predictions reflected the dominant seasonal climates. In the winter, the dominant climatic features influencing Taiwan's temperature are the

Table 3 - Mean seasonal temperatures between 1971 and 2000 for Chia-Yi, Alishan, and Yushan Weather Stations (data source: Taiwan Central Weather Bureau)

\begin{tabular}{|c|c|c|c|c|c|c|}
\hline Station & Location & Elevation (m) & Spring $\left({ }^{\circ} \mathrm{C}\right)$ & Summer $\left({ }^{\circ} \mathrm{C}\right)$ & Fall $\left({ }^{\circ} \mathrm{C}\right)$ & Winter $\left({ }^{\circ} \mathrm{C}\right)$ \\
\hline Chia-Yi & $\begin{array}{l}23^{\circ} 29^{\prime} 51^{\prime \prime} \mathrm{N} \\
120^{\circ} 25^{\prime} 28^{\prime \prime} \mathrm{E}\end{array}$ & 27 & 22.6 & 27.9 & 24.0 & 16.8 \\
\hline Alishan & $\begin{array}{l}23^{\circ} 30^{\prime} 37^{\prime \prime} \mathrm{N} \\
120^{\circ} 48^{\prime} 18^{\prime \prime} \mathrm{E}\end{array}$ & 2413 & $\begin{array}{l}10.9 \\
(11.0)^{\mathrm{a}}\end{array}$ & $\begin{array}{l}14.2 \\
(14.2)\end{array}$ & $\begin{array}{l}11.8 \\
(12.0)\end{array}$ & $\begin{array}{l}6.7 \\
(6.9)\end{array}$ \\
\hline Yushan & $\begin{array}{l}23^{\circ} 29^{\prime} 21^{\prime \prime} \mathrm{N} \\
120^{\circ} 57^{\prime} 06^{\prime \prime} \mathrm{E}\end{array}$ & 3845 & $\begin{array}{l}3.3 \\
(3.2)\end{array}$ & $\begin{array}{l}7.3 \\
(7.2)\end{array}$ & $\begin{array}{l}5.7 \\
(5.5)\end{array}$ & $\begin{array}{l}-0.6 \\
(-0.6)\end{array}$ \\
\hline
\end{tabular}



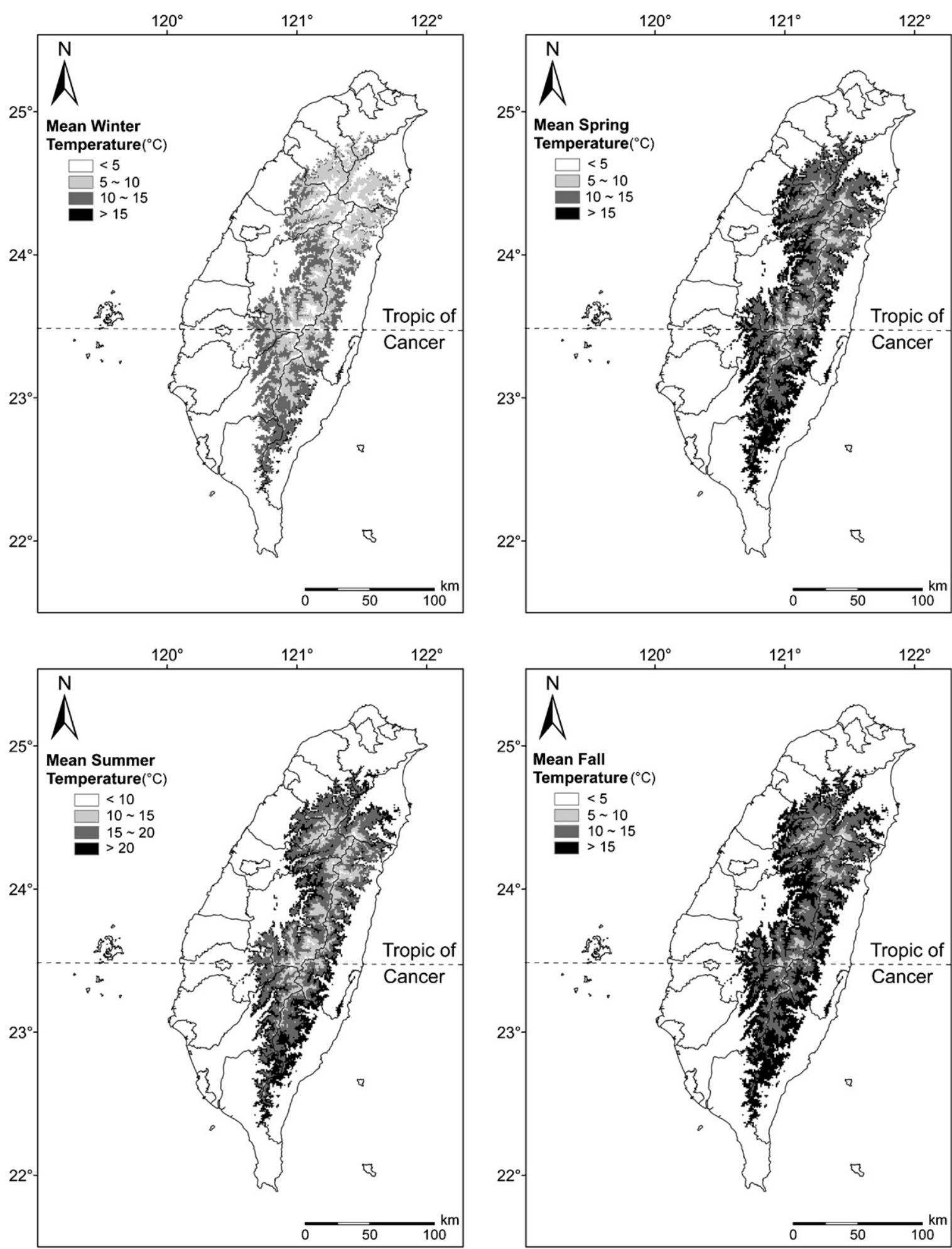

Fig. 6 - Predicted mean seasonal temperature patterns for the mountain regions of Taiwan.

northeast monsoons carrying cold and wet air, whereas hot winds from the south and southwest are the dominant influences in the summer. The uneven warming and cooling of the mountain regions, as predicted by our models, also reflected the influences of the geographic location and regional climate features.

\section{Discussion}

A potential problem with nonparametric smoothing is that a fitted model might have excessive EDF (i.e., an overfitted model). Such a model will have a small bias, but a large prediction variance and a low generalization capability 
(bias-variance tradeoff, Hastie et al., 2001). In this study, although the total EDF of each fitted model were large relative to the number of data, both the adjusted $R^{2}$, which penalizes excessive EDF, and the cross-validation results indicated that our models were not over-fitted. Furthermore, model analyses and spatial interpolation results indicated that the collective behavior of our models realistically reflected the influences of the geographic location, dominant seasonal climates, terrain characteristics, and their interactions.

One important finding of this study is that the temperatureelevation relationship was nonlinear during the first 3 calendar months, the higher the elevation, the higher the lapse rate. The nonlinearity was also confirmed by replacing the parametric term in Model I with a nonparametric smoother. The smoother's EDF for the first 3 months were 2.37, 2.02, and 2.03 (i.e., nearly a second-order polynomial). For the remaining months, except April, the EDF were close to 1. The EDF for April were 1.52, suggesting a nonlinear trend. Based on AIC, however, we selected Model I.

Fox and Bloom (1994) also reported nonlinear seasonal and annual temperature-elevation relationships in the Peruvian Andes. They considered that in tropics a moist adiabatic rate (nonlinear) described the observed temperature changes with increasing elevation better than a dry adiabatic rate (linear) did. However, as the nonlinear relationships occurred only during the first 3 months, we consider that the uneven cooling and warming of temperatures along the steep altitudinal gradient during those 3 months (Table 3 and Fig. 5), due to the interactions of geographic and terrain characteristics, was the main cause of the nonlinear trends.

An important application of our models will be to derive approximated cumulative thermal-time contour maps. Together with species distribution information, such maps will enable us to establish the relationships between the alpine species and the thermal environments, which in turn will allow us to assess the flora integrity under various climate change scenarios.

Our models are also useful for re-evaluating existing ecological theories and identifying areas that may be vulnerable under climate change. For example, Su (1984) suggested that a higher tree line in the central alpine region (elevation $\geq 3000 \mathrm{~m}$ ) near the Tropic of Cancer, where the majority of the high peaks are located (Figs. 1 and 2), is due to the Massenerhebung effect (or mountain mass effect, see Barry, 1992 for a discussion on the concept). If Su's interpretation is correct, we expect that the central alpine region will not be as cold during the winter. Based on the seasonal predictions, we calculated the deviation of each point's summer and winter temperature difference from the average difference between the two seasons (about $8.6^{\circ} \mathrm{C}$ ). A negative deviation would indicate that the point is not as cold in winter (i.e., a lower summer-winter contrast). The result supported the interpretation, as the negative values were mainly concentrated in that alpine region (Fig. 7). For points in the central alpine region with a negative deviation (mean $3188 \mathrm{~m}$ ), the mean predicted summer and winter temperatures were 11.5 and $3.8^{\circ} \mathrm{C}$, respectively. In contrast, for those with a positive deviation in the northern alpine region (mean $3198 \mathrm{~m}$ ), the mean predicted summer and winter temperatures were 11.2 and $1.2^{\circ} \mathrm{C}$, respectively.

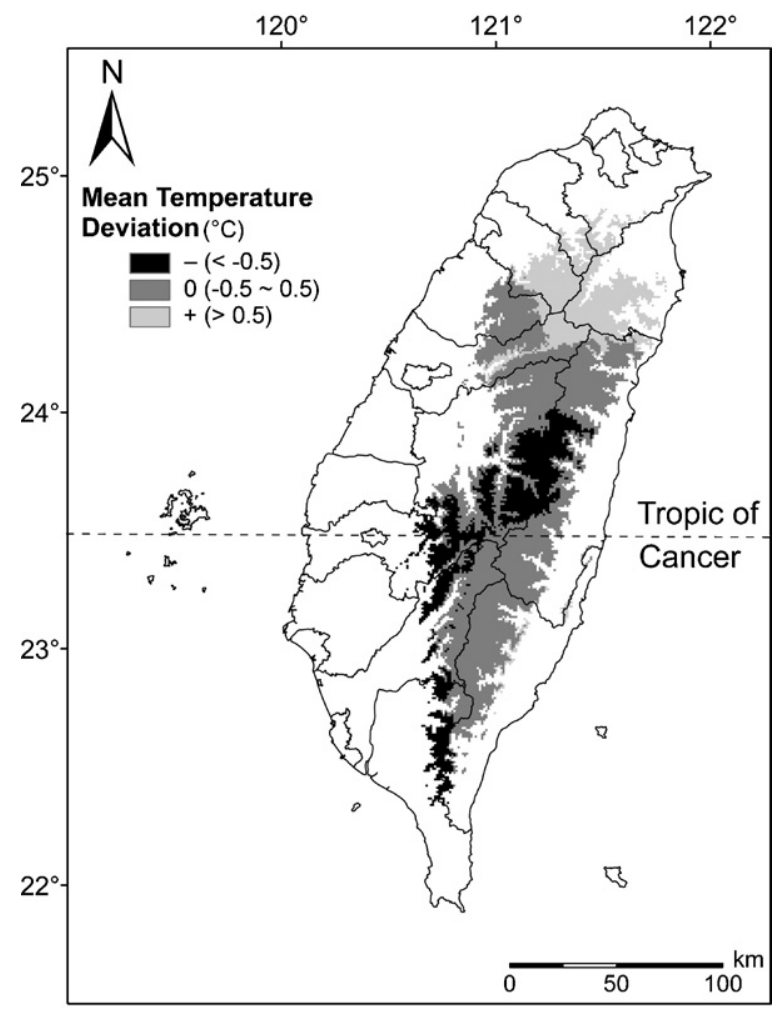

Fig. 7 - Spatial patterns of the summer-winter temperature deviations from the mean difference between the predicted mean summer and winter temperatures.

As the florae of Taiwan's alpine regions are similar, our models also suggest that the florae of the central and southern alpine regions would likely be more vulnerable to future temperature increases than that of the northern region. The central and southern alpine regions already have a higher predicted mean winter temperature (Figs. 5 and 6), further winter temperature increases would likely affect the chilling requirements of plant species in those regions (Saxe et al., 2001).

Not surprisingly, the influential stations were all the ones located at the edges of the mountain systems, where the geographic location and terrain characteristics interact strongly, and where we only have a few stations (Fig. 1). The close connection between Cook's distance and the deleted residual suggests that predictions will also be less reliable for the edge areas. Predicting temperatures for the mountain region on the east side of the Central Mountain Range will be particularly challenging, as the entire Central Mountain Range slopes toward the east. The temperature gradient is therefore steeper on that side than it is on the western side. In addition, the eastern side of the divide is usually drier than the western side, as the mountain range intercepts moisture from the west, which also affects the lapse rate (Barry, 1992). The southern end of the Central Mountain Range is another area of concern. In the summer, that area heats up first, and the region is still influenced by warm southerly winds in the winter (Figs. 5 and 7). The altitudinal gradient is also quite steep as one travels from the plain areas to the mountain 
regions (Fig. 1). Moreover, the mountain flora of that region has a more southerly affinity than that of the rest of Taiwan. Thus, to assess accurately the future integrity of and to protect effectively that region's mountain flora will require more localized temperature models.

Modeling temperature patterns over a complex terrain usually suffers from the lack of data from remote areas and this study is no exception. Fortunately, we have a relatively dense network of quality stations in the Snow Mountain Range and the northern and central parts of the Central Mountain Range, as well as a good representation along the steep gradient. We were therefore able to develop models with realistic behaviors for most of Taiwan's mountain regions. It is evident that to improve our models, we will need to have more data from the edge areas of our mountain regions. However, it is exactly because of their inaccessibility that we do not have permanent meteorology stations in those areas in the first place. One solution to the dilemma is to place temporary observation points in those areas, and then model the spatial relationships between the temporary ones and the nearest permanent stations (e.g., Lookingbill and Urban, 2003; Sansom and Tait, 2004). Such an approach will enable us to improve island-wide models, as well as to develop more localized models.

\section{Acknowledgements}

This study was supported by National Science Council of Taiwan (NSC 96-2621-B-002-001 and NSC 96-2313-B-002-014). We thank Taiwan Forestry Bureau for providing the digital terrain model and Taiwan Central Weather Bureau for providing the meteorological data. We also thank two anonymous reviewers for their critical comments.

\section{REFEREN CES}

Barry, G.R., 1992. Mountain Weather and Climate, 2nd ed. Routledge, London.

Boer, E.P.J., de Beurs, K.M., Hartkamp, A.D., 2001. Kriging and thin plate splines for mapping climate variables. Int. J. Appl. Earth Obs. 3, 146-154.

Craven, P., Wahba, G., 1979. Smoothing noisy data with spline functions: estimating the correct degree of smoothing by the method of generalized cross validation. Numer. Math. 31, 377-403.

Cressie, N.A.C., 1993. Statistics for Spatial Data. Wiley, New York.

Eubank, R.L., 1985. Diagnostics for smoothing splines. J. Roy. Stat. Soc. B 47, 332-341.

Fox, A.N., Bloom, A.L., 1994. Snowline altitude and climate in the Peruvian Andes $\left(5-17^{\circ} \mathrm{S}\right)$ at present and during the latest Pleistocene glacial maximum. J. Georg. 103, 867-885.

Grieser, J., Trömel, S., Schönwiese, C.-D., 2002. Statistical time series decomposition into significant components and application to European temperature. Theor. Appl. Climatol. 71, 171-183.

Halloy, S.R.P., Mark, A.F., 2003. Climate-change effects on alpine plant biodiversity: a New Zealand perspective on quantifying the threat. Arct. Antarct. Alp. Res. 35, 248-254.

Haslett, J.R., 1997. Mountain ecology: organism responses to environmental change, an introduction. Global Ecol. Biogeogr. Lett. 6, 3-6.
Hastie, T.J., Tibshirani, R.J., 1990. Generalized Additive Models. Chapman \& Hall, New York.

Hastie, T., Tibshirani, R., Friedman, J., 2001. Elements of Statistical Learning: Data Mining, Inference, and Prediction. Springer, New York.

Hsu, H.-H., Chen, C.-T., 2002. Observed and projected climate change in Taiwan. Meteorol. Atmos. Phys. 79, 87-104.

Hutchinson, M.F., 1998a. Interpolation of rainfall data with thin plate smoothing splines. Part I. Two dimensional smoothing of data with short range correlation. J. Geogr. Infor. Decis. Anal. 2, 152-167.

Hutchinson, M.F., 1998b. Interpolation of rainfall data with thin plate smoothing splines. Part II. Analysis of topographic dependence. J. Geogr. Infor. Decis. Anal. 2, 168-185.

Jarvis, C.H., Stuart, N., 2001. A comparison among strategies for interpolating maximum and minimum daily air temperatures. Part II. The interaction between number of guiding variables and the type of interpolation method. J. Appl. Meteorol. 40, 1075-1084.

Kapos, V., Rhind, J., Edwards, M., Price, M.F., Ravilious, C., 2000. Developing a map of the world's mountain forests. In: Price, M.F., Butt, N. (Eds.), Forests in Sustainable Mountain Development: A State-of-Knowledge Report for 2000. CAB International, Wallingford, pp. 4-9.

Körner, C., 2002. Mountain biodiversity, its causes and function: an overview. In: Körner, C., Spehn, E.M. (Eds.), Mountain Biodiversity: A Global Assessment. Parthenon, New York, pp. 3-20.

Körner, C., Spehn, E.M. (Eds.), 2002. Mountain Biodiversity: A Global Assessment. Parthenon, New York.

Lookingbill, T.R., Urban, D.L., 2003. Spatial estimation of air temperature differences for landscape-scale studies in montane environments. Agric. For. Meteorol. 114, 141-151.

MacArthur, R.H., 1972. Geographical Ecology: Patterns in the Distribution of Species. Harper \& Row, New York.

McKenney, D.W., Pedlar, J.H., Papadopol, P., Hutchinson, M.F., 2006. The development of 1901-2000 historical monthly climate models for Canada and the United States. Agric. For. Meteorol. 138, 69-81.

Pounds, J.A., Fogden, M.L.P., Campbell, J.H., 1999. Biological response to climate change on a tropical mountain. Nature 398, 611-615.

Price, D.T., McKenney, D.W., Nalder, I.A., Hutchinson, M.F., Kesteven, J.L., 2000. A comparison of two statistical methods for spatial interpolation of Canadian monthly mean climate data. Agric. For. Meteorol. 101, 81-94.

R Development Core Team, 2007. R: A Language and Environment for Statistical Computing. R Foundation for Statistical Computing, Vienna.

Rolland, C., 2003. Spatial and seasonal variations of air temperature lapse rates in alpine regions. J. Clim. 16, 1032-1046.

Sansom, J., Tait, A., 2004. Estimation of long-term climate information at locations with short-term data records. J. Appl. Meteorol. 43, 915-923.

Saxe, H., Cannell, M.G.R., Johnsen, Ø., Ryan, M.G., Vourlitis, G., 2001. Tree and forest functioning in response to global warming. New Phytol. 149, 369-400.

Stone, M., 1974. Cross-validatory choice and assessment of statistical predictions. J. Roy. Stat. Soc. Ser. B 36, 111-147.

$\mathrm{Su}$, H.J., 1984. Studies on the climate and vegetation types of the natural forests in Taiwan (II). Altitudinal vegetation zones in relation to temperature gradient. Q. J. Chin. For. 17, 57-73.

Tait, A., Henderson, R., Turner, R., Zheng, X., 2006. Thin plate smoothing spline interpolation of daily rainfall for New Zealand using a climatological rainfall surface. Int. J. Climatol. 26, 2097-2115. 
Thomas, C.D., Cameron, A., Green, R.E., Bakkenes, M., Beaumont, L.J., Collingham, Y.C., Erasmus, B.F.N., de Siqueira, M.F., Grainger, A., Hannah, L., Hughes, L., Huntley, B., van Jaarsveld, A.S., Midgley, G.F., Miles, L., Ortega-Huerta, M.A., Peterson, A.T., Phillips, O.L., Williams, S.E., 2004. Extinction risk from climate change. Nature 427, 145-148.

Vislocky, R.L., Fritsch, J.M., 1995. Generalized additive models versus linear regression in generating probabilistic MOS forecasts of aviation weather parameters. Weather Forecast $10,669-680$

Wahba, G., 1990. Spline Models for Observational Data. SIAM, Philadelphia.

Wood, S.N., 2003. Thin plate regression splines. J. Roy. Stat. Soc. B 65, 95-114.

Wood, S.N., 2006. Generalized Additive Models: An Introduction. R. Chapman \& Hall, Boca Raton. 